\title{
A Comparative Study of Perceptions and Use of Google Scholar and Academic Library Discovery Systems
}

\section{Kyong Eun Oh and Mónica Colón-Aguirre}

\begin{abstract}
Google Scholar and academic library discovery systems are both popular resources among academic users for finding scholarly information. By conducting an online survey with 975 users from more than 20 public research universities across the United States, this study comparatively investigates how and why academic users use these two resources. Results show that the ways participants used both resources were similar, and both were perceived as highly accessible and useful. Academic library discovery systems' perceived comprehensiveness, subjective norm, loyalty, and intended use were higher than Google Scholar, while Google Scholar's perceived ease of use, system quality, and satisfaction were higher than that of academic library discovery systems.
\end{abstract}

\section{Introduction}

The relationship between Google and academic institutions in the United States is symbiotic, with Google products taking a more central role in finding information and, in many cases, replicating databases and library search tools. ${ }^{1}$ Particularly, Google Scholar (GS), the company's specialized search engine for academic materials, has sometimes been seen as a competitor or even a threat to academic libraries since its release in $2004 .{ }^{2}$ However, despite initial concerns, GS has become an important addition to existing library resources, and the integration of GS has created a relationship of coexistence with other databases rather than a predatory one. ${ }^{3}$ Currently, both GS and academic library discovery systems are main search tools for academic users who aim to find scholarly information. ${ }^{4}$ However, despite their popularity and similarities, there exists a lack of empirical studies that comparatively analyze how and why academic users use both systems to find information resources. In particular, a comparative analysis of academic users' perceptions regarding the relative strengths and weaknesses of the two systems has not yet been fully explored.

In this study, library discovery system is defined as a system located in the library website that provides a single point of access to search library resources via a single search box. This work also considers library discovery systems as a unit, independent of the various products used at

\footnotetext{
${ }^{*}$ Kyong Eun Oh is an Associate Professor in the School of Library and Information Science at Simmons University; email: kyongeun.oh@simmons.edu. Mónica Colón-Aguirre is an Assistant Professor in the Department of Interdisciplinary Professions (Library Science Program) at East Carolina University; email: colonaguirrem17@ ecu.edu. (C) 2019 Kyong Eun Oh and Mónica Colón-Aguirre.
} 
different institutions, since the study's main considerations are users' perceptions of library resources and GS as entities, not the qualities of individual discovery systems' specific products. Understanding how and why these systems are used by academic users is important, since libraries seek to reach a balance between user expectations and quality of information resources, while making cost-effective decisions. GS is still not a replacement for library resources, but it is a popular tool for patrons, one that seems to become more popular every day while shaping users' expectations. ${ }^{5}$ Google products are perceived as innovative and have high visibility among library users; therefore, libraries need to be aware of not only Google products but also how its own products and services fare against the search engine giant to stay relevant to users' needs. Part of this awareness is exploring the ways in which library patrons both use and perceive their information retrieval systems. Therefore, this study investigates and compares academic users' perceptions and use of these two systems: the library discovery system and Google Scholar.

\section{Literature Review}

\section{Studies on Google Scholar vs. Scholarly Databases}

There has been continued interest in comparing GS with libraries' scholarly databases in terms of quantity and quality of search results. As time has passed, different results have been found. Soon after GS' debut, Callicott and Vaughn searched sample research topics in GS, their library's OPAC, and scholarly databases to compare the search results. ${ }^{6}$ The researchers found that the library's OPAC and scholarly databases had better searchability and provided more relevant search results than GS. ${ }^{7}$ Similarly, Gardner and Eng compared simple search results of GS and multiple scholarly databases, reporting that, although GS retrieved more results, those resources were less current and not all of the results were scholarly or relevant. ${ }^{8}$ Levine-Clark and Kraus compared the search results of GS with Chemical Abstract Services (CAS) and found that GS retrieved more results. ${ }^{9}$ However, while GS performed better for topical search, CAS performed better for compound search and name search. ${ }^{10}$ More recently, Walters compared the precision and recall of the simple search results of GS with those of eight scholarly databases and found that GS had better precision and recall. ${ }^{11}$ Similarly, Bramer, Giustini, Kramer, and Anderson compared GS with PubMed and reported that GS had higher recall but slightly lower precision than PubMed..$^{12}$ Ştirbu, Thirion, Schmitz, Haesbroeck, and Greco also compared GS with three bibliographic databases in geography and found that GS returned more results and contained a number of relevant results. ${ }^{13}$ In short, previous studies found that GS retrieved higher numbers of results. In terms of quality, earlier studies tend to report that scholarly databases provided more relevant results, while more recent studies report that GS retrieved more relevant results.

Other studies have specifically focused on the coverage of GS and scholarly databases by searching a limited list of items in these tools and checking whether they are discoverable in each. Overall, previous studies showed that GS had better coverage than subscription databases. For example, Howland et al. compared the coverage of GS with subscription databases and found that GS provided better coverage of materials. ${ }^{14}$ Bramer et al. compared GS with PubMed and reported that GS had higher coverage than PubMed. ${ }^{15}$ In addition, several researchers observed the improvement of GS' coverage over time. Meier and Conkling compared the coverage of GS with an indexing database from the 1950s to 2007 by decade and found that GS' coverage got better over time. ${ }^{16}$ Similarly, Chen, who compared the coverage of GS with eight databases, stated that, in five years, the coverage of GS increased greatly. ${ }^{17}$ 


\section{Studies on Google Scholar vs. Federated Search Tools or Library Discovery Systems}

Additional studies have compared GS with academic libraries' federated search tools, which allow users to search selected scholarly databases simultaneously. Haya et al., who compared GS with a federated search tool, stated that GS had better usability and provided more satisfaction because of its simple and convenient search interface. ${ }^{18}$ Haya et al. also found that GS retrieved higher quality content. ${ }^{19}$ Similarly, Georgas, who compared GS with a federated search tool, stated that students found that GS was easier to use and that it provided more relevant results than a federated search tool. ${ }^{20}$ When the author actually assessed the quality of sources, she found that the total quality of resources was quite similar. ${ }^{21}$ Georgas also compared students' search behaviors in both search tools and found that their behaviors are similar in terms of types of queries, the average number of searches, and the average length of research sessions. ${ }^{22}$

There have also been studies that compared GS with a library discovery system, which allows users to search the complete library materials via a single search box (rather than conducting separate searches based on collection or material types such as databases or OPAC). After comparing GS with a library discovery system as well as three scholarly databases, Timpson and Sansom reported that, while GS is simpler and easier to use, GS showed the poorest performance among the search tools. ${ }^{23}$ Similarly, Asher, Duke, and Wilson compared the search efficacy of GS, library discovery system, and scholarly databases, reporting that search efficacy of library tools were better than GS. ${ }^{24}$ Overall, previous studies showed that GS was simpler and more convenient to use than federated search tools or library discovery systems. However, in terms of the quality or relevance of search results, studies that compared GS with federated search tools reported that GS was better, while studies that compared GS with library discovery systems stated that library discovery systems were better. While closely related to this study, these previous studies primarily focused on the interfaces or features of the tools as well as the relevance or quality of the search results rather than the use or perception of the two systems.

\section{Studies on the Use of Google Scholar}

A few studies have examined how academic users employ GS. Herrera analyzed library logs and transaction data and found that users in the social sciences and the sciences used GS more frequently than users in the humanities. ${ }^{25}$ The researcher also reported that there was no clear difference in the frequency of GS use among undergraduates, graduate students, or professors. ${ }^{26} \mathrm{Wu}$ and Chen interviewed 32 graduate students to investigate how they perceive and use GS. ${ }^{27}$ The researchers found that participants primarily use GS to find full-text documents, journal articles, and English resources. ${ }^{28} \mathrm{~A}$ majority of students found GS easy to use, and science and technology students were most in favor of GS. ${ }^{29}$ The researchers also reported that more than 80 percent of participants viewed the quality of information from library websites to be higher than the quality of information from GS, and 50 percent of participants responded that they could retrieve more relevant information from library websites. ${ }^{30}$ Similarly, Cothran investigated how graduate students perceive and use GS by conducting an online survey based on the Technology Acceptance Model (TAM). ${ }^{31}$ The researcher found that participants' perceived usefulness, loyalty, and perceived ease of use were positively associated with the intended use of GS. ${ }^{32}$ In addition, perceived ease of use, subjective norm, and comprehensiveness were positively related to the perceived usefulness of GS. ${ }^{33}$ 
In summary, a number of studies have compared GS and library search tools in terms of their searchability, coverage, and interfaces. Some research studies have also explored how academic users use GS. Particularly, Cothran's study is closely related to the present study. ${ }^{34}$ However, those studies primarily focused on GS. Georgas is one of the few researchers who compared how academic users perceive and use GS and a library search tool. ${ }^{35}$ However, the participants of the study included only undergraduate students, and the sample size was rather small $(n=32)$. In addition, it compared GS with a federated search tool rather than discovery tools. In contrast, the present study comparatively analyzes how academic users in the United States perceive and use GS and academic library discovery systems and in which aspects one resource is regarded as better than the other, while using a larger sample size that includes undergraduates, graduates, postgraduates, and faculty members, all of whom are important and frequent users.

\section{Research Questions}

This study is guided by the following research questions:

- RQ1. How do academic users use GS and academic library discovery systems?

- RQ2. How do academic users perceive GS and academic library discovery systems in terms of their ease of use, accessibility, system quality, usefulness, comprehensiveness, subjective norm, satisfaction, loyalty, and intended use?

- RQ3. What are the relative strengths and weaknesses of the two systems?

\section{Methods}

\section{Participants and Procedures}

Data was collected from 1,650 academic users through an online survey. The participants included undergraduates, graduate students, postdoctoral students, and professors. To recruit participants, the researchers chose a random sample of 20 universities from the list of public research universities in the United States with very high research output, as defined by the Carnegie Classification of Institutions. These 20 universities are presented in table 1 . After selecting 20 institutions, the researchers contacted administrative representatives in all departments with a request to disseminate a link to the survey. All of those contacted were asked to participate voluntarily. The researchers' personal networks were also used by asking people who work at public research universities and posting the link to the online survey to social media sites. As a result, the participants of the survey included people outside of the 20 universities. After deleting incomplete responses, 975 responses were analyzed. Participants' demographic information is displayed in table 2.

\begin{tabular}{|l|}
\multicolumn{1}{|c|}{$\begin{array}{c}\text { TABLE 1 } \\
\text { List } \mathbf{2 0} \text { Universities }\end{array}$} \\
\hline Institutions \\
\hline Oregon State University \\
\hline Pennsylvania State University \\
\hline University at Albany, SUNY \\
\hline University of Alabama-Huntsville \\
\hline University of California-Berkeley \\
\hline University of California-Santa Cruz \\
\hline University of Central Florida \\
\hline University of Houston \\
\hline University of Illinois-Chicago \\
\hline University of Louisville \\
\hline University of Maryland-College Park \\
\hline University of Massachusetts-Amherst \\
\hline University of New Mexico \\
\hline University of Pittsburgh-Pittsburgh \\
\hline University of South Carolina-Columbia \\
\hline University of South Florida-Tampa \\
\hline University of Tennessee \\
\hline University of Virginia \\
\hline University of Washington-Seattle \\
\hline Wayne State University \\
\hline
\end{tabular}




\begin{tabular}{|l|c|}
\hline \multicolumn{2}{|c|}{ TABLE 2} \\
Demographics of Participants \\
\hline Gender & \\
\hline Male & $311(31.9 \%)$ \\
\hline Female & $655(67.2 \%)$ \\
\hline Age Group & \\
\hline Under 20 & $62(6.4 \%)$ \\
\hline $20 s$ & $494(50.7 \%)$ \\
\hline $30 s$ & $240(24.6 \%)$ \\
\hline $40 s$ & $91(9.3 \%)$ \\
\hline $50 s$ & $51(5.2 \%)$ \\
\hline Over 60 & $31(3.2 \%)$ \\
\hline Status & \\
\hline Undergraduate & $159(16.3 \%)$ \\
\hline Master's & $229(23.5 \%)$ \\
\hline Doctoral & $383(39.3 \%)$ \\
\hline Postdoctoral & $26(2.7 \%)$ \\
\hline Faculty & $162(16.6 \%)$ \\
\hline Field of Study & \\
\hline Arts \& Humanities & $84(8.7 \%)$ \\
\hline Sciences & $303(31.2 \%)$ \\
\hline Social Sciences & $400(41.9 \%)$ \\
\hline Others & $184(19.0 \%)$ \\
\hline
\end{tabular}

\section{Measurement Instruments}

The first section of the survey asked for participants' perceptions and use of GS, the second section asked for participants' perceptions and use of their own academic library discovery system, and the third section asked for participants' demographic information. To investigate use of the two systems, participants were asked about length of use, frequency of use, frequency of finding a specific type of resource, and ease of finding a specific type of resource. The participants' perceptions of the two systems as a venue to find scholarly information resources were examined using nine variables from Cothran's (2011) study, which was based on Davis' (1989) TAM: a tool that examines users' acceptance or rejection of a new information technology and the impact of specific system characteristics on this behavior. ${ }^{36}$ The researchers decided to use variables in TAM because they are extensively used and applied in various fields and specifically decided to use nine variables in Cothran's (2011) study because they are well established and pertinent to our study. The nine variables employed in this study were: (1) ease of use, "the degree to which a person believes that using a particular system would be free of effort"; (2) accessibility, "the ease with which information can be accessed or extracted from the system"; (3) system quality, "the usability of a system or a quality attribute that assesses how easy user interfaces are to use"; (4) perceived usefulness, "the degree to which a person believes that using a particular system would enhance his or her job performance"; (5) comprehensiveness, "the degree to which the system provides all necessary information"; (6) subjective norm, "the social influence by people who are important to the user on system use"; (7) satisfaction, "a positive affective response by the user resulting from their interaction with the system"; (8) loyalty, "a non-random behavior, expressed over time, which depends on psychological processes and closeness to brand commitment"; and (9) intended use, "the stated likelihood that the user will continue to use the venue for their research in the future." ${ }^{37}$ Users were asked to rate their perception of these nine qualities of GS and of their own academic library discovery system on a Likert scale. The reliability of each variable was established using Cronbach's alpha, which is used to measure the extent to which a set of questions in a survey measure the same variable (that is to say, internal consistency). ${ }^{38}$ The results of the reliability test showed that each variable's reliability is higher than .75 , which is commonly acceptable in social science research.

\section{Results}

\section{Length and Frequency of Use}

Most participants (71.6\%) used GS for one to six years, and more than 60 percent of the participants used academic library discovery systems for one to six years $(61.3 \%)$. As shown in figure 1, the length of experience using GS and academic library discovery systems was similar. 


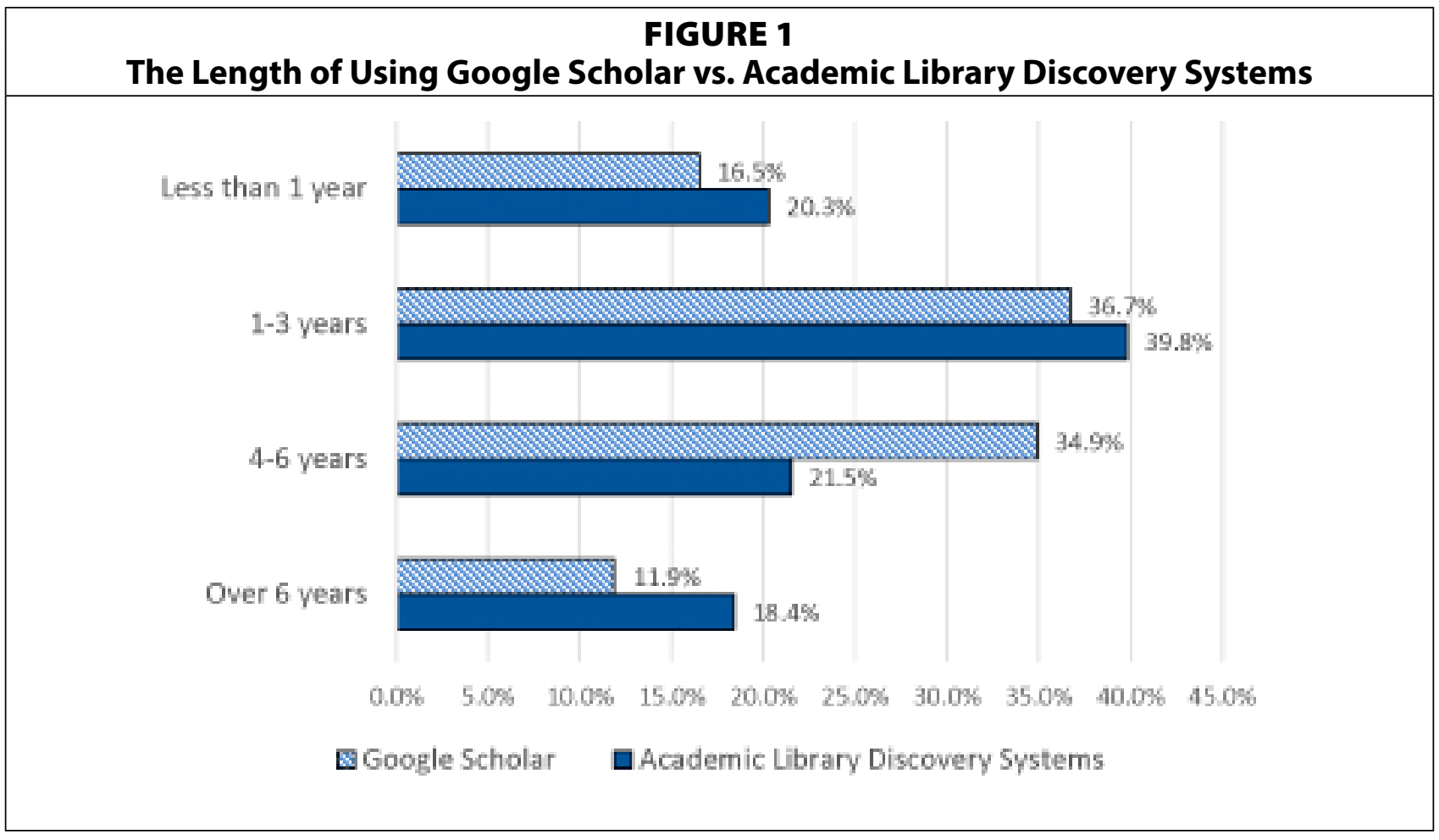

Most participants used GS before (94.1\%), and there were slight increasing proportions of participants who reported using GS infrequently, monthly, and weekly. In the case of academic library discovery systems, most participants used academic library discovery systems before (96.9\%), and increasing proportions of participants used their academic library discovery systems infrequently, monthly, and weekly. Overall, most participants used both systems frequently, as shown in figure 2.

\section{FIGURE 2}

The Frequency of Using Google Scholar vs. Academic Library Discovery Systems

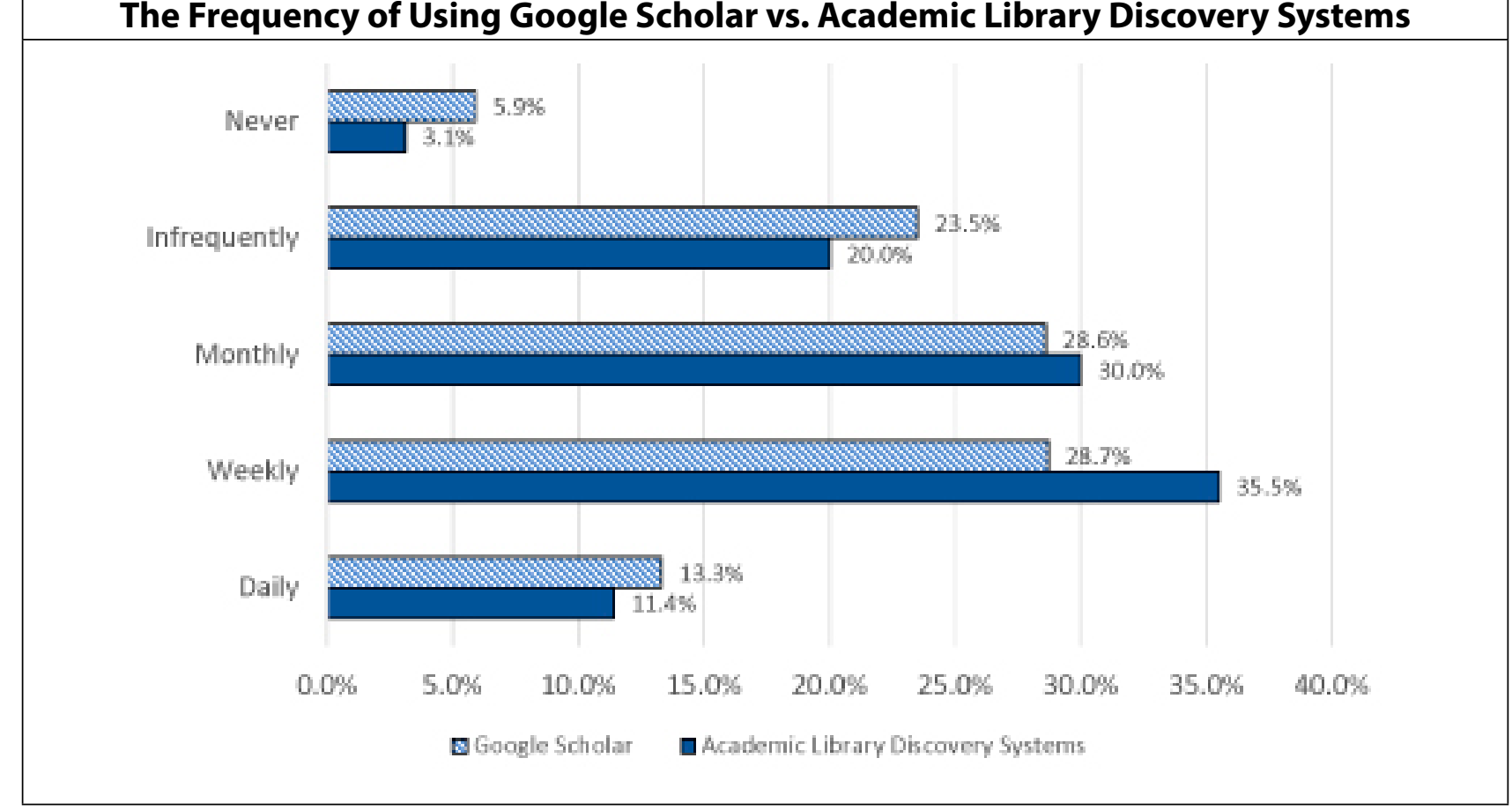




\section{Frequency of Finding a Specific Type of Resource}

Forty-five percent of participants used GS weekly or daily with the specific intent of finding journal articles. Considering the fact that less than 10 percent of participants used GS weekly or daily to find other types of resources (in other words, e-books, conference materials, data collections, government documents, and reports), this result suggests that participants frequently used GS with the primary intention of finding journal articles. In the case of academic library discovery systems, 48.2 percent of participants used the system weekly or daily to look for journal articles. This result shows that journal articles were also the major type of resource participants look for in the academic library discovery systems. Similar to GS, more than 70

\begin{tabular}{|c|c|c|c|}
\hline \multicolumn{4}{|c|}{$\begin{array}{l}\text { TABLE } 3 \\
\text { Frequency of Finding a Specific Type of Resource }\end{array}$} \\
\hline & & Google Scholar & Academic Library Discovery Systems \\
\hline \multirow[t]{5}{*}{ Ebooks } & Never & $289(29.6 \%)$ & $218(22.4 \%)$ \\
\hline & Infrequently & $435(44.6 \%)$ & $353(36.2 \%)$ \\
\hline & Monthly & $158(16.2 \%)$ & $250(25.6 \%)$ \\
\hline & Weekly & $67(6.9 \%)$ & $118(12.1 \%)$ \\
\hline & Daily & $11(1.1 \%)$ & $18(1.8 \%)$ \\
\hline \multirow[t]{5}{*}{ Journal Articles } & Never & $52(5.3 \%)$ & $42(4.3 \%)$ \\
\hline & Infrequently & $184(18.9 \%)$ & $153(15.7 \%)$ \\
\hline & Monthly & $275(28.2 \%)$ & $292(29.9 \%)$ \\
\hline & Weekly & $303(31.1 \%)$ & $346(35.5 \%)$ \\
\hline & Daily & $136(13.9 \%)$ & $124(12.7 \%)$ \\
\hline \multirow[t]{5}{*}{ Conference Materials } & Never & $343(35.2 \%)$ & $365(37.4 \%)$ \\
\hline & Infrequently & $381(39.1 \%)$ & $348(35.7 \%)$ \\
\hline & Monthly & $147(15.1 \%)$ & $155(15.9 \%)$ \\
\hline & Weekly & $64(6.6 \%)$ & $61(6.3 \%)$ \\
\hline & Daily & $15(1.5 \%)$ & $14(1.4 \%)$ \\
\hline \multirow[t]{5}{*}{ Data Collections } & Never & 475 (48.7\%) & 435 (44.6\%) \\
\hline & Infrequently & 334 (34.3\%) & $325(33.3 \%)$ \\
\hline & Monthly & $121(12.4 \%)$ & $143(14.7 \%)$ \\
\hline & Weekly & $26(2.7 \%)$ & $38(3.9 \%)$ \\
\hline & Daily & $5(0.5 \%)$ & $11(1.1 \%)$ \\
\hline \multirow{5}{*}{$\begin{array}{l}\text { Government } \\
\text { Documents }\end{array}$} & Never & 435 (44.6\%) & 415 (42.6\%) \\
\hline & Infrequently & $342(35.1 \%)$ & $353(36.2 \%)$ \\
\hline & Monthly & $142(14.6 \%)$ & 137 (14.1\%) \\
\hline & Weekly & $34(3.5 \%)$ & $42(4.3 \%)$ \\
\hline & Daily & $7(0.7 \%)$ & $9(0.9 \%)$ \\
\hline \multirow[t]{5}{*}{ Reports } & Never & 367 (37.6\%) & $428(43.9 \%)$ \\
\hline & Infrequently & 349 (35.8\%) & 347 (35.6\%) \\
\hline & Monthly & 179 (18.4\%) & $126(12.9 \%)$ \\
\hline & Weekly & $60(6.2 \%)$ & $42(4.3 \%)$ \\
\hline & Daily & $6(0.6 \%)$ & $13(1.3 \%)$ \\
\hline
\end{tabular}


percent of participants said that they either infrequently or never used their academic library discovery systems to look for other types of resources. However, 13.9 percent said they looked for e-books either weekly or daily. Overall, the frequency of finding a particular type of resource via these two systems was surprisingly similar. The results showed that participants found (1) journal articles most frequently in both systems, (2) e-books slightly more frequently via academic library discovery systems than GS, and (3) other types of resources infrequently in both venues, as shown in table 3 .

\section{Perceived Ease of Finding a Specific Type of Resource}

The perceived ease of finding a specific type of resource was asked with a seven-point Likert scale, ranging from 1 (very difficult) to 7 (very easy). In GS, journal articles were perceived as the easiest type of resource to find, followed by ebooks, conference materials, and reports. Journal articles were also perceived as the easiest type of resource to find in academic library discovery systems, followed by ebooks and then conference materials. Overall, the rankings of the perceived ease of finding a particular type of resource were very similar in both systems. However, a series of paired $t$-tests showed statistically significant differences between the two systems, as shown in table 4 . On the one hand, it was easier to find journal articles $(t(958)=$ $2.57, p<.05)$ ), conference materials $(t(936)=3.09, p<.01))$, and reports $(t(930)=3.03, p<.01))$ via GS than academic library discovery systems. On the other hand, participants responded that ebooks $(t(951)=-5.45, p$ $<.001)$ ) and data collections $(t(930)=-3.07, p<.01))$ were easier to find via academic library discovery systems than GS. No significant differences were found in the perceived ease of finding government documents.

\begin{tabular}{|l|c|c|c|}
\hline \multicolumn{4}{|c|}{ TABLE 4 } \\
\hline & $\begin{array}{c}\text { Perceived Ease of Finding a Specific Type of Resource } \\
\text { (Likert scale 1-7) }\end{array}$ \\
\hline & $\begin{array}{c}\text { Google } \\
\text { Scholar }\end{array}$ & $\begin{array}{l}\text { Academic Library } \\
\text { Discovery Systems }\end{array}$ & $t$-value \\
\hline Ebooks & 4.39 & 4.71 & $-5.45^{* * *}$ \\
\hline Journal Articles & 5.57 & 5.41 & $2.57^{*}$ \\
\hline Conference Materials & 4.31 & 4.15 & $3.00^{* * *}$ \\
\hline Data Collections & 3.97 & 4.11 & $-3.07^{* *}$ \\
\hline Government Documents & 4.12 & 4.11 & 0.29 \\
\hline Reports & 4.19 & 4.04 & $3.03^{* *}$ \\
\hline${ }^{*} p<.05,{ }^{* *} p<.01,{ }^{* * *} p<.001$ & \\
\hline
\end{tabular}

\section{Perceptions of Google Scholar vs. Academic Library Discovery Systems}

Although results were close for both systems, paired sample tests showed that GS had an edge over academic libraries in terms of ease of use, system quality, and satisfaction. Meanwhile, academic libraries had an edge over GS in terms of comprehensiveness, subjective norm, loyalty and intended use.

\section{Ease of Use}

Participants perceived GS as easier to use than academic library discovery systems, $(t(960)=$ $14.08, p<.001)$. In particular, participants reported that GS was easier to learn than academic library discovery systems, contained easier-to-understand terminologies than those in academic library discovery systems, and that interacting with GS did not require as much mental effort as academic library discovery systems. 


\section{System Quality}

Participants' perceived system quality of GS was significantly higher than academic library discovery tools $(t(957)=9.30, p<.001)$. Participants also found that the user interface design of GS was friendlier than that of their academic library discovery systems, and navigating GS was easier than navigating their academic library discovery systems. However, participants thought academic library discovery systems improved the quality of their research compared to GS.

\section{Comprehensiveness}

Participants perceived academic library discovery systems as more comprehensive than GS $(t(960)=-6.37, p<.001)$. In particular, participants reported that their academic library discovery systems had enough resources for their study more often than GS did, their academic library discovery systems covered a wider range of topics related to their particular interests than GS, and they more often found exactly what they were looking for while using their academic library discovery systems compared to GS.

\section{Subjective Norm}

Participants reported that people whom they think are credible suggested that they should use both systems. However, the paired sample $t$-test showed that participants' perceived subjective norm of the academic library discovery systems was significantly higher than GS $(t(971)=-13.45, p<.001)$.

\section{Satisfaction}

Participants' satisfaction in using GS was significantly higher than their academic library discovery systems $(t(960)=2.76, p<.01)$. Particularly, participants were more satisfied with the accessibility of GS and their overall experience with GS than with their academic library discovery systems. However, participants were more satisfied with the quality and number of results found via the academic library discovery systems than GS. The values for the statement "I think I made the correct decision to use the venue" were also higher for the academic library discovery systems than GS. In brief, although GS' satisfaction was higher than academic library discovery systems in general, there were some mixed results in responses to specific questions about satisfaction.

\section{Loyalty}

Participants' loyalty to academic library discovery systems was significantly higher than their loyalty to GS $(t(959)=-3.89, p<.0001)$. More specifically, participants trusted the academic library discovery systems more and considered themselves to be more loyal to the academic library discovery systems than to GS. In addition, the scores for the statement "This venue is the first place I go to start my academic work" were higher for the academic library discovery systems than for GS.

\section{Intended Use}

The paired sample $t$-test also showed that intended use of the academic library discovery systems was significantly higher than that of GS $(t(963)=-4.20, p<.001)$. Particularly, participants reported that they are more likely to continue using their academic library discovery systems in the future than GS. 
Accessibility and Usefulness

Participants viewed both systems as highly accessible and useful. The paired sample $t$-test showed that there was no statistically significant difference in participants' perceived accessibility or usefulness between the two systems.

Table 5 displays participants' perceptions of GS and academic library discovery systems measured by nine variables.

\begin{tabular}{|c|c|c|c|c|c|c|c|}
\hline Perceptions o & $\begin{array}{c}\text { TABLE } 5 \\
\text { le Scholar and Academic Library }\end{array}$ & scol & y $s$ & er & (Lik & tsc & 1-7) \\
\hline Variables & Survey Items & Goog & le Sch & olar & $\begin{array}{l}\text { Acad } \\
\text { Disco }\end{array}$ & $\begin{array}{l}\text { emic } L \\
\text { very } S\end{array}$ & $\begin{array}{l}\text { brary } \\
\text { stems }\end{array}$ \\
\hline & & M & SD & $\mathbf{a}$ & M & SD & $\mathbf{a}$ \\
\hline Ease of Use & & 5.66 & 1.11 & 0.93 & 4.88 & 1.41 & 0.94 \\
\hline & I find the venue easy to use. & 5.78 & 1.25 & & 4.87 & 1.61 & \\
\hline & Learning to use the venue is easy for me. & 5.90 & 1.16 & & 4.99 & 1.55 & \\
\hline & $\begin{array}{l}\text { Interacting with the venue does not } \\
\text { require a lot of mental effort. }\end{array}$ & 5.70 & 1.28 & & 4.66 & 1.60 & \\
\hline & $\begin{array}{l}\text { I find it easy to get the venue to do } \\
\text { what I want it to do. }\end{array}$ & 5.32 & 1.35 & & 4.68 & 1.66 & \\
\hline & $\begin{array}{l}\text { I find it easy to understand the terms } \\
\text { used throughout the venue. }\end{array}$ & 5.57 & 1.28 & & 5.20 & 1.46 & \\
\hline Accessibility & & 5.54 & 1.14 & 0.77 & 5.46 & 1.22 & 0.75 \\
\hline & $\begin{array}{l}\text { In general, I can find full articles using } \\
\text { the venue. }\end{array}$ & 5.14 & 1.51 & & 5.63 & 1.45 & \\
\hline & $\begin{array}{l}\text { The venue makes information easy to } \\
\text { access. }\end{array}$ & 5.60 & 1.35 & & 5.15 & 1.53 & \\
\hline & $\begin{array}{l}\text { I can access Google Scholar from } \\
\text { anywhere. }\end{array}$ & 5.88 & 1.29 & & 5.61 & 1.50 & \\
\hline System Quality & & 5.55 & 1.19 & 0.86 & 5.04 & 1.34 & 0.84 \\
\hline & $\begin{array}{l}\text { The user interface design of the venue } \\
\text { is friendly. }\end{array}$ & 5.63 & 1.33 & & 4.75 & 1.57 & \\
\hline & It is easy to navigate the venue. & 5.69 & 1.27 & & 4.70 & 1.61 & \\
\hline & $\begin{array}{l}\text { Using the venue improves the quality } \\
\text { of my research. }\end{array}$ & 5.33 & 1.44 & & 5.66 & 1.41 & \\
\hline Usefulness & & 5.44 & 1.31 & 0.94 & 5.44 & 1.32 & 0.90 \\
\hline & $\begin{array}{l}\text { Using the venue makes it easier to do } \\
\text { my research. }\end{array}$ & 5.59 & 1.42 & & 5.46 & 1.51 & \\
\hline & I find the venue useful in my research. & 5.64 & 1.42 & & 5.68 & 1.43 & \\
\hline & $\begin{array}{l}\text { I can find many relevant articles with } \\
\text { one search in the venue. }\end{array}$ & 5.22 & 1.48 & & 5.00 & 1.69 & \\
\hline & $\begin{array}{l}\text { The resources in the venue relate well } \\
\text { to my research. }\end{array}$ & 5.29 & 1.35 & & 5.58 & 1.35 & \\
\hline
\end{tabular}




\begin{tabular}{|c|c|c|c|c|c|c|c|}
\hline Perceptions of Go & $\begin{array}{c}\text { TABLE } 5 \\
\text { gle Scholar and Academic Library }\end{array}$ & co & y & en & Li & sci & 1-7) \\
\hline Variables & Survey Items & Goog & le Sch & olar & $\begin{array}{l}\text { Acad } \\
\text { Discc }\end{array}$ & $\begin{array}{l}\text { emic } L \\
\text { very } S\end{array}$ & $\begin{array}{l}\text { orary } \\
\text { stems }\end{array}$ \\
\hline & & $M$ & SD & $a$ & $\mathbf{M}$ & SD & $\mathbf{a}$ \\
\hline Comprehensiveness & & 4.95 & 1.38 & 0.89 & 5.35 & 1.33 & 0.89 \\
\hline & $\begin{array}{l}\text { The venue has enough resources for my } \\
\text { study. }\end{array}$ & 4.62 & 1.66 & & 5.30 & 1.50 & \\
\hline & $\begin{array}{l}\text { The venue covers a wide range of } \\
\text { topics in my particular interest. }\end{array}$ & 5.32 & 1.38 & & 5.60 & 1.36 & \\
\hline & $\begin{array}{l}\text { I often find exactly what I am looking } \\
\text { for while using the venue. }\end{array}$ & 4.90 & 1.56 & & 5.15 & 1.53 & \\
\hline Subjective Norm & $\begin{array}{l}\text { People whom I think are credible } \\
\text { suggest that I should use the venue. }\end{array}$ & 4.82 & 1.54 & $\mathrm{~N} / \mathrm{A}$ & 5.64 & 1.44 & $\mathrm{~N} / \mathrm{A}$ \\
\hline Satisfaction & & 5.36 & 1.16 & 0.93 & 5.21 & 1.27 & 0.92 \\
\hline & $\begin{array}{l}\text { I think I made the correct decision to } \\
\text { use the venue. }\end{array}$ & 5.31 & 1.29 & & 5.73 & 1.34 & \\
\hline & $\begin{array}{l}\text { I am satisfied with the quality of the } \\
\text { results I have received from the venue. }\end{array}$ & 5.16 & 1.43 & & 5.43 & 1.45 & \\
\hline & $\begin{array}{l}\text { I am satisfied with the quantity of the } \\
\text { results I have received from the venue. }\end{array}$ & 5.19 & 1.41 & & 5.27 & 1.44 & \\
\hline & $\begin{array}{l}\text { I am satisfied with the interface of the } \\
\text { venue. }\end{array}$ & 5.42 & 1.35 & & 4.67 & 1.69 & \\
\hline & $\begin{array}{l}\text { I am satisfied with the accessibility of } \\
\text { the venue. }\end{array}$ & 5.76 & 1.24 & & 5.26 & 1.53 & \\
\hline & $\begin{array}{l}\text { I am satisfied with the overall } \\
\text { experience with the venue. }\end{array}$ & 5.28 & 1.39 & & 4.91 & 1.57 & \\
\hline Loyalty & & 4.48 & 1.70 & 0.91 & 4.82 & 1.59 & 0.87 \\
\hline & $\begin{array}{l}\text { The venue is the first place I go to start } \\
\text { my academic work. }\end{array}$ & 4.29 & 2.17 & & 4.47 & 2.20 & \\
\hline & $\begin{array}{l}\text { The venue is my favorite place to search } \\
\text { for scholarly articles. }\end{array}$ & 4.37 & 2.12 & & 4.33 & 2.12 & \\
\hline & I trust the venue. & 5.28 & 1.44 & & 5.97 & 1.22 & \\
\hline & $\begin{array}{l}\text { I consider myself to be loyal to the } \\
\text { venue. }\end{array}$ & 3.97 & 1.85 & & 4.54 & 1.80 & \\
\hline Intended Use & & 5.50 & 1.44 & 0.85 & 5.78 & 1.40 & 0.88 \\
\hline & $\begin{array}{l}\text { I intend to continue using the venue in } \\
\text { the future. }\end{array}$ & 5.78 & 1.36 & & 5.91 & 1.40 & \\
\hline & $\begin{array}{l}\text { I would use the venue for any research } \\
\text { which requires scholarly articles. }\end{array}$ & 5.21 & 1.70 & & 5.64 & 1.58 & \\
\hline
\end{tabular}


The summary of the paired $t$ tests, which shows the differences in perceptions of GS and academic library discovery systems, is presented in table 6.

\section{Discussion}

Similarities in Perceptions and Use of Two Systems

This study comparatively examined how academic users in the United States perceive and use GS and academic library discovery systems. The results showed that the way participants use both venues are surprisingly similar.

Almost all participants have used both GS $(94.1 \%)$ and academic library discovery systems (96.9\%) before, and about 60 to 70 percent of participants have been using both systems between one to six years. The results of this study showed that GS has become a more common tool for academic users when compared to Cothran's results, which found 26.7 percent of respondents had never used GS before. This study also found that both resources are frequently used by participants, with more than 40 percent of the participants indicating that they use both systems either weekly or daily.

A number of studies reported that journal articles are the primary type of information resource for academic users. ${ }^{39}$ This study also found that the journal article is the most frequently found type of resource in both systems. These findings align with $\mathrm{Wu}$ and Chen's study, in which a majority of participants (31 out of 32) used GS to search for journal articles. ${ }^{40}$ The fact that journal articles are the main type of information resource academic users find indicates that ease of finding journal articles is crucial to academic users who are choosing tools to look for information resources. In fact, our study found that journal articles were not only the most frequently found type of information resource in both systems but also the type of resource that was easiest to find in both venues, although they were easier to find in GS.

This study also found that participants perceived both systems as highly accessible and useful, and there were no statistically significant differences in the accessibility or perceived usefulness of both systems. Since perceived usefulness is one of the key factors in choosing and using an information system, these findings explain why both systems are so popular among academic users. ${ }^{41}$

\section{Differences in Perceptions of Two Systems Strengths of Google Scholar}

Google Scholar is viewed as easier to use than academic library discovery systems. This finding is consistent with previous research studies. ${ }^{42}$ In fact, ease of use has often been mentioned as one of the main strengths of GS. ${ }^{43}$ In addition, past studies reported that ease of use is one of the primary factors that impact users' acceptance and use of an information system. ${ }^{44}$ In 
short, although ease of use was one of nine variables in this study, the impact of the ease of using the search tool should not be underestimated.

The system quality of GS was also perceived as better than academic library discovery tools, with participants viewing the usability of GS as better than library discovery systems. This supports findings of previous studies, which found that participants preferred GS' usability to other search tools in academic libraries. ${ }^{45}$ According to these studies, GS provides a simple and convenient interface as well as smooth and quick searching, which seems to have contributed to its usability. Google tools are also viewed as user-friendly and mobile-friendly. ${ }^{46}$ In contrast, library website designs were reported to be difficult to use by some users ${ }^{47}$ However, other studies reported almost equal numbers of participants who preferred the interface of GS and search tools in academic library websites. ${ }^{48}$ Not surprisingly, system quality has been positively associated with users' acceptance and use of an information system. ${ }^{49}$

GS also received a higher score in satisfaction than academic library discovery systems. Since satisfaction is closely related to the ease of using an information system, which is also relevant to system quality, it is understandable that GS, which was perceived as easier to use and having better system quality, resulted in more satisfaction for participants..$^{50}$ A number of previous studies reported that, if the user is satisfied with the experience of using an information system, it is very likely that they will use it again. ${ }^{51}$

\section{Strengths of Academic Library Discovery Systems}

Academic library discovery systems were perceived as more comprehensive than GS. This finding deviated from findings of some previous studies, which reported that GS is more comprehensive than scholarly databases ${ }^{52}$ This might mean that academic library discovery systems' comprehensiveness has improved over time. There also may be inconsistencies, since the coverage of GS varies across disciplines. ${ }^{53}$ In addition, it is worth noting that most of the previous studies compared GS with scholarly databases rather than library discovery tools, which search all information resources that can be accessed via library websites. In this study, participants from various disciplines perceived that academic library discovery systems are more comprehensive than GS.

Academic library discovery systems also had a higher subjective norm, which means that people who are important to the participants, such as professors, librarians, colleagues, or friends, had a bigger influence on the use of academic library discovery systems than GS. In this study, participants were specifically asked to what extent people whom the participants think are credible suggest using this information system. In brief, the finding indicates that library discovery systems were more highly recommended by other people than GS. In fact, previous research studies showed that sometimes students use library resources primarily because the course instructor specifically requires them to use it. ${ }^{54}$ Since it is believed by many that libraries provide more credible and higher quality resources than GS, it is possible that people suggested using library discovery systems rather than GS. ${ }^{55}$

Participants were also more loyal to academic library discovery systems than to GS. This might be because loyalty is based on previous experiences, and there were more participants who have been using academic library websites (18.4\%) for more than 6 years than GS $(11.9 \%)$. This is an interesting finding because loyalty to GS and academic library discovery systems has not been comparatively examined before. Not surprisingly, loyalty has been found to have a substantial influence on the acceptance and use of an information system. ${ }^{56}$ In fact, 
in this study, the intended use for academic library discovery systems was higher than GS, which means that participants are more willing to use academic library discovery systems in the future than GS. This finding that participants were more loyal to and had greater intent to use academic library discovery systems than GS explains why academic libraries did not lose academic users to GS, despite early concerns about losing them.

\section{Conclusion}

This study comparatively analyzed academic users' perceptions and use of GS and academic library discovery systems. The results show that there are similarities in how participants use both resources, which implies the level of use and the purpose of use for both systems are very similar. In addition, both systems were perceived as easily accessible and useful.

Beyond these similarities, this study also found statistically significant differences in how participants perceive GS and academic library discovery systems. On the one hand, GS was perceived as being easier to use, providing better system quality, and resulting in higher satisfaction than academic library discovery systems. On the other hand, academic library discovery systems were perceived as more comprehensive. Participants also had higher subjective norm as well as loyalty to academic library discovery systems and were more intent to use them than to use GS. Although both resources were perceived as better than the other in certain aspects, overall there was no clear preference for either. This aligns with findings from previous studies, which reported this coexistence and even reported that each resource facilitated the access and use of the other resource. ${ }^{57}$ In summary, it is important and necessary to regard each resource not as a competitor but as a good model to learn from for improvement, especially since both are used in similar ways but have different aspects that are preferred by users. However, the participants of this study were recruited from public research universities with high research activity, so academic users at other kinds of institutions may have different experiences and perceptions.

This large-scale, quantitative study deepens our knowledge of how and why academic users employ GS and academic library discovery systems. In addition, this study contributes to our understanding of the similarities and differences between the two systems by directly comparing a broad range of perceptions and use. This study also helps increase understanding of the perspectives of actual users, which is crucial for system design. In particular, the participants of this study included undergraduate students, graduate students, and professors, while most previous studies focused on only undergraduates or graduate students while neglecting doctoral students and faculty members, who are important and frequent users. ${ }^{58}$ In the future, it would be useful to further analyze and compare subgroups of the participants (that is, undergraduates, master's students, doctoral students, and professors) to gain a more in-depth understanding of how and why academic users employ both systems. In addition, investigating similarities and differences in the perceptions and use of both systems among academic users in different disciplines will enrich our understanding. Moreover, testing the TAM model in both systems to comparatively analyze the relationships among variables and especially identifying primary factors that influence the use of both systems will provide a more thorough understanding of how and why academic users employ both systems.

\section{Acknowledgment}

We wish to thank Erin Butler for her assistance in data collection. We would also like to thank all the participants of the study. 


\section{Notes}

1. Siva Vaidhyanathan, The Googlization of Everything (And Why We Should Worry), (Oakland, CA: University of California Press, 2011).

2. José Luis Ortega, Academic Search Engines: A Quantitative Outlook (Oxford, UK: Chandos Publishing, 2014).

3. Geoffrey Little, "How I Learned to Stop Worrying and Love Google," Journal of Academic Librarianship 37, no. 5 (2011): 443-44.

4. Helen Georgas, "Google vs. the Library (Part III): Assessing the Quality of Sources Found by Undergraduates," portal: Libraries and the Academy 15, no. 1 (2015): 133-61.

5. Larry Johnson et al., NMC Horizon Report: 2015 Library Edition (Austin, TX: The New Media Consortium, 2015), available online at https://www.learntechlib.org/p/151822/ [accessed 9 April 2018].

6. Burton Callicott and Debbie Vaughn, "Google Scholar vs. Library Scholar: Testing the Performance of Schoogle," Internet Reference Services Quarterly 10, no. 3/4 (2005): 71-88.

7. Callicott and Vaughn, "Google Scholar vs. Library Scholar."

8. Susan Gardner and Susanna Eng, "Gaga over Google? Scholar in the Social Sciences," Library Hi Tech News 22, no. 8 (2005): 42-45.

9. Michael Levine-Clark and Joseph Kraus, "Finding Chemistry Information Using Google Scholar: A Comparison with Chemical Abstracts Service," Science \& Technology Libraries 27, no. 4 (2007): 3-17.

10. Levine-Clark and Kraus, "Finding Chemistry Information Using Google Scholar."

11. William H. Walters, "Comparative Recall and Precision of Simple and Expert Searches in Google Scholar and Eight Other Databases," portal: Libraries and the Academy 11, no. 4 (2011): 971-1006.

12. Wichor M. Bramer et al., "The Comparative Recall of Google Scholar versus PubMed in Identical Searches for Biomedical Systematic Reviews: A Review of Searches Used in Systematic Reviews," Systematic Reviews 2, no. 1 (2013): 115.

13. Simona Ştirbu et al., "The Utility of Google Scholar When Searching Geographical Literature: Comparison with Three Commercial Bibliographic Databases," Journal of Academic Librarianship 41, no. 3 (2015): 322-29.

14. Jared L. Howland et al., "How Scholarly Is Google Scholar? A Comparison to Library Databases," College $\mathcal{E}$ Research Libraries 70, no. 3 (2009): 227-34.

15. Bramer et al., "The Comparative Recall of Google Scholar versus PubMed," 115.

16. John J. Meier and Thomas W. Conkling, "Google Scholar's Coverage of the Engineering Literature: An Empirical Study," Journal of Academic Librarianship 34, no. 3 (2008): 196-201.

17. Xiaotian Chen, "The Declining Value of Subscription-Based Abstracting and Indexing Services in the New Knowledge Dissemination Era," Serials Review 36, no. 2 (2010): 79-85.

18. Glenn Haya, Else Nygen, and Wilhelm Widmark, "Metalib and Google Scholar: A User Study," Online Information Review 31, no. 3 (2007): 365-75.

19. Haya, Nygen, and Widmark, "Metalib and Google Scholar."

20. Helen Georgas, "Google vs. the Library: Student Preferences and Perceptions When Doing Research Using Google and a Federated Search Tool," portal: Libraries and the Academy 13, no. 2 (2013): 165-85.

21. Georgas, "Google vs. the Library (Part III)," 133-61.

22. Helen Georgas, "Google vs. the Library (Part II): Student Search Patterns and Behavior Using Google and a Federated Search Tool," portal: Libraries and the Academy 14, no. 4 (2014): 503-32.

23. Helen Timpson and Gemma Sansom, "A Student Perspective on E-Resource Discovery: Has the Google Factor Changed Publisher Platform Searching Forever?" Serials Librarian 61, no. 2 (2011): 253-66.

24. Andrew D. Asher, Lynda M. Duke, and Suzanne Wilson, "Paths of Discovery: Comparing the Search Effectiveness of EBSCO Discovery Service, Summon, Google Scholar, and Conventional Library Resources," College E Research Libraries 74, no. 5 (2013): 464-88.

25. Gail Herrera, "Google Scholar Users and User Behaviors: An Exploratory Study," College E Research Libraries 72, no. 4 (2011): 316-31.

26. Herrera, "Google Scholar Users and User Behaviors."

27. Ming-der Wu and Shih-chuan Chen, "Graduate Students Appreciate Google Scholar, but Still Find Use for Libraries," Electronic Library 32, no. 3 (2014): 375-89.

28. Wu and Chen, "Graduate Students Appreciate Google Scholar, but Still Find Use for Libraries."

29. Wu and Chen, "Graduate Students Appreciate Google Scholar, but Still Find Use for Libraries."

30. Wu and Chen, "Graduate Students Appreciate Google Scholar, but Still Find Use for Libraries."

31. Tanya Cothran, "Google Scholar Acceptance and Use among Graduate Students: A Quantitative Study," Library \& Information Science Research 33, no. 4 (2011): 293-301. 
32. Cothran, "Google Scholar Acceptance and Use among Graduate Students."

33. Cothran, "Google Scholar Acceptance and Use among Graduate Students."

34. Cothran, "Google Scholar Acceptance and Use among Graduate Students."

35. Georgas, "Google vs. the Library," 165-85.

36. Cothran, "Google Scholar Acceptance and Use among Graduate Students," 293-301; Fred D. Davis, "Perceived Usefulness, Perceived Ease of Use, and User Acceptance of Information Technology," MIS Quarterly 13, no. 3 (1989): 319-40.

37. Cothran, "Google Scholar Acceptance and Use among Graduate Students," 294, 296-97.

38. Mohsen Tavakol and Reg Dennick, "Making Sense of Cronbach's Alpha," International Journal of Medical Education 2 (2011): 53-55.

39. Julie Carpenter, "Researchers of Tomorrow: The Research Behavior of Generation Y Doctoral Students," Information Services \& Use 32, no. 1/2 (2012): 3-17; Xi Niu et al., "National Study of Information Seeking Behavior of Academic Researchers in the United States," Journal of the American Society for Information Science E Technology 61, no. 5 (2010): 869-90.

40. Wu and Chen, "Graduate Students Appreciate Google Scholar, but Still Find Use for Libraries," 375-89.

41. Cothran, "Google Scholar Acceptance and Use among Graduate Students," 293-301; John H. Heinrichs et al., "Determining Factors of Academic Library Web Site Usage," Journal of the American Society for Information Science \& Technology 58, no. 14 (2007): 2325-34; Yong-Mi Kim, “Users' Perceptions of University Library Websites: A Unifying View," Library \& Information Science Research 33, no. 1 (2011): 63-72.

42. Georgas, "Google vs. the Library," 165-85; Haya, Nygen, and Widmark, "Metalib and Google Scholar," 365-75; Ya Wang and Pamela Howard, "Google Scholar Usage: An Academic Library's Experience," Journal of Web Librarianship 6, no. 2 (2012): 94-108.

43. Georgas, "Google vs. the Library," 165-85; Georgas, "Google vs. the Library (Part II)," 503-32; Wang and Howard, "Google Scholar Usage," 94-108; Wu and Chen, "Graduate Students Appreciate Google Scholar, but Still Find Use for Libraries," 375-89.

44. Lynn Sillipigni Connaway, Timothy J. Dickey, and Marie L. Radford, “'If It Is Too Inconvenient I'm Not Going After It': Convenience as a Critical Factor in Information-Seeking Behaviors," Library \& Information Science Research 33, no. 3 (2011): 179-90; Cothran, "Google Scholar Acceptance and Use among Graduate Students," 293-301.

45. Haya, Nygen, and Widmark, "Metalib and Google Scholar," 365-75; Wu and Chen, "Graduate Students Google Scholar Acceptance and Use among Graduate Students," 375-89.

46. Joy M. Perrin, review of The Complete Guide to Using Google in Libraries, ed. Carol Smallwood, portal: Libraries and the Academy 16, no. 3 (July 2016): 649-50.

47. Kim, "Users' Perceptions of University Library Websites," 63-72.

48. Xi Niu and Bradley M. Hemminger, "A Study of Factors That Affect the Information-Seeking Behavior of Academic Scientists," Journal of the American Society for Information Science E Technology 63, no. 2 (2012): 336-53.

49. Su-Chao Chang and Feng-Cheng Tung, "An Empirical Investigation of Students' Behavioural Intentions to Use the Online Learning Course Websites," British Journal of Education Technology 39, no. 1 (2008): 71-83.

50. Luis V. Casaló, Carlos Flavián, and Miguel Guinalíu, "The Role of Perceived Usability, Reputation, Satisfaction and Consumer Familiarity on the Website Loyalty Formation Process," Computers in Human Behavior 24, no. 2 (2008): 325-45; Cothran, "Google Scholar Acceptance and Use among Graduate Students," 293-301; Heinrichs et al., "Determining Factors of Academic Library Web Site Usage," 2325-34.

51. Cothran, "Google Scholar Acceptance and Use among Graduate Students," 293-301; Heinrichs et al., "Determining Factors of Academic Library Web Site Usage," 2325-34.

52. Bramer et al., "The Comparative Recall of Google Scholar versus PubMed," 115; Howland et al., "How Scholarly Is Google Scholar?" 227-34.

53. Chris Neuhaus et al., "The Depth and Breadth of Google Scholar: An Empirical Study," portal: Libraries and the Academy 6, no. 2 (2006): 127-41.

54. Mónica Colón-Aguirre and Rachel A. Fleming-May, "'You Just Type in What You Are Looking For': Undergraduates' Use of Library Resources vs. Wikipedia," Journal of Academic Librarianship 38, no. 6 (2012): 391-99.

55. Colón-Aguirre and Fleming-May, "You Just Type in What You Are Looking For," 391-99; Wu and Chen, "Graduate Students Appreciate Google Scholar, but Still Find Use for Libraries," 375-89.

56. Cothran, "Google Scholar Acceptance and Use among Graduate Students," 293-301.

57. Howland et al., "How Scholarly Is Google Scholar?" 227-34; Wu and Chen, "Graduate Students Appreciate Google Scholar, but Still Find Use for Libraries," 375-89; Georgas, "Google vs. the Library (Part II)," 503-32; Georgas, "Google vs. the Library (Part III)," 133-61; Herrera, "Google Scholar Users and User Behaviors," 316-31; Wang and Howard, "Google Scholar Usage," 94-108.

58. Herrera, "Google Scholar Users and User Behaviors," 316-31. 